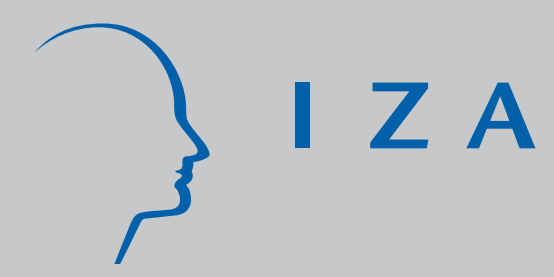

IZA DP No. 2308

The Role of Marriage in Immigrants' Human Capital Investment under Liquidity Constraints

Sarit Cohen-Goldner

Chemi Gotlibovski

Nava Kahana

September 2006 


\title{
The Role of Marriage in Immigrants' Human Capital Investment under Liquidity Constraints
}

\author{
Sarit Cohen-Goldner \\ Bar-Ilan University \\ Chemi Gotlibovski \\ Academic College of Tel-Aviv Yaffo \\ Nava Kahana \\ Bar-Ilan University \\ and IZA Bonn
}

Discussion Paper No. 2308

September 2006

\author{
IZA \\ P.O. Box 7240 \\ 53072 Bonn \\ Germany \\ Phone: +49-228-3894-0 \\ Fax: +49-228-3894-180 \\ Email: iza@iza.org
}

\begin{abstract}
Any opinions expressed here are those of the author(s) and not those of the institute. Research disseminated by IZA may include views on policy, but the institute itself takes no institutional policy positions.

The Institute for the Study of Labor (IZA) in Bonn is a local and virtual international research center and a place of communication between science, politics and business. IZA is an independent nonprofit company supported by Deutsche Post World Net. The center is associated with the University of Bonn and offers a stimulating research environment through its research networks, research support, and visitors and doctoral programs. IZA engages in (i) original and internationally competitive research in all fields of labor economics, (ii) development of policy concepts, and (iii) dissemination of research results and concepts to the interested public.
\end{abstract}

IZA Discussion Papers often represent preliminary work and are circulated to encourage discussion. Citation of such a paper should account for its provisional character. A revised version may be available directly from the author. 


\section{ABSTRACT \\ The Role of Marriage in Immigrants' Human Capital Investment under Liquidity Constraints}

This paper presents a two-period human capital investment model of married and single immigrants under binding liquidity constraints, which explains alternative patterns in the host country's labor market. These patterns are also compared to those of natives who face a perfect capital market. By extending Eckstein and Weiss' model (2004) from the case of single immigrants with accessibility to a perfect capital market to the case of creditconstrained immigrant families, it is shown that the comparative advantage in investment that determines which spouse will invest more in local skills depends on his/her imported human capital growth rate rather than on its level. This comparative advantage can lead to full or partial specialization in work and investment activities within immigrant households. However, the level invested by each spouse is non-increasing with the level of the imported human capital of the spouse with the comparative advantage in investment, whereas it is nondecreasing with the level of imported human capital of the other spouse. A comparison of pre and post marriage investment indicates that the spouse with the comparative advantage in investment will increase his/her investment in human capital after his/her marriage, whereas the other spouse will decrease it. The more efficient investment due to marriage enables the achievement of a Pareto improvement.

JEL Classification: D10, J24, J61

Keywords: $\quad$ human capital investment, immigrants, marriage, binding liquidity constraints

Corresponding author:

Nava Kahana

Department of Economics

Bar-Ilan University

52900 Ramat-Gan

Israel

E-mail: kahanan@mail.biu.ac.il

\footnotetext{
* We thank Yoram Weiss for his valuable comments. We also benefited from comments of the participants at a Tel-Aviv University labor seminar.
} 


\section{Introduction}

Can marriage help immigrants facilitate binding liquidity constraints upon arrival to a new country by enabling an efficient human capital investment in local skills, thereby leading to a Pareto improvement? Do immigrant couples' human capital investment decisions differ from those of their native counterparts? This paper studies the optimal human capital investment decisions of married immigrants who face binding liquidity constraints compared to those of single immigrants and those of natives who have access to a perfect capital market.

The paper provides a theoretical framework for what is known in the empirical literature as the Family Investment Hypothesis (henceforth FIH). According to the FIH, credit-constrained immigrant families adopt a household strategy in order to finance their post-immigration human capital investment such that one spouse invests in host countryspecific human capital and the other spouse undertakes labor market activities that finance their current consumption. Binding credit-constraints thus create a link between the husband and the wife's labor supply.

Despite growing interest in the FIH, to the best of our knowledge, there is no formal model that explains the relations between the immigrant husband and his wife's investment and work strategies. The purpose of this paper is to fill this niche. As stated by Cobb-Clark and Crossley (2004), any formal version of the FIH must address the household members' comparative advantage in work and investment activities.

In our model, assuming that the pre and post-immigration human capital are complements in their influence on the immigrant's earning capacity in the host country ${ }^{1}$, the household member's comparative advantage in investment in local skills emerges from

\footnotetext{
${ }^{1}$ Recent studies found empirical evidence that locally acquired and imported human capital are complements in "producing earnings". For example, Duleep and Regets (1999) found that learning the host-country language increases the transferability of imported skills.
} 
his/her relatively high imported human capital growth rate. The growth rate of imported human capital reflects the immigrant's adjustment process to a new-country economy which may depend on his/her imported occupation, country of origin, etc. ${ }^{2}$ This comparative advantage can lead to partial specialization of one or both spouses or to full specialization within the immigrants' household. ${ }^{3}$

There exists extensive empirical literature that attempts to test the FIH. ${ }^{4}$ The major aim of these papers is to determine whether immigrant's family faces and responds to binding liquidity constraints, based on the husband and wife's performance in the new labor market. Any evidence that the secondary worker in the family works more, works longer hours, and foregoes his/her investment in human capital by initially taking better paying but "dead-end" jobs compared to the primary worker was considered as a support for the hypothesis and for the existence of binding liquidity constraints, and vice versa. However, this literature a priori classified the husband and wife as the primary and secondary workers, respectively, though this classification was not supported by any formal economic considerations. ${ }^{5}$

According to our model, each spouse's optimal investment level in local skills depends on his/her imported human capital growth rate and not solely on his/her imported human capital level. Moreover, when two individuals get married (form a family) the optimal investment level of the spouse with the higher imported human capital growth rate increases, whereas his/her partner's investment level decreases, independent of the partition

\footnotetext{
${ }^{2}$ Eckstein and Weiss (2004) presented this feature in their model in the context of a single immigrant's investment in human capital when facing a perfect capital market.

${ }^{3}$ In the literature on marriage, Weiss (1997) explored the benefit of marriage under liquidity constraints when the human capital investment technology and the utility function are linear. In his model the comparative advantage in investment, for example in schooling, emerges from the direct costs of investment. However, due to the linearity of the technology, this model leads to full specialization. Our model describes also investment in activities in which both spouses can choose to invest partially like investment on the job.

${ }^{4}$ For example: Long (1980); Beach and Worswick (1993); Duleep and Sanders (1993); Worswick (1996, 1999); Baker and Benjamin (1997); Blau et al. (2003); Duleep and Dowhan (2002) Cobb-Clark and Crossley (2004).

${ }^{5}$ Cobb-Clark and Crossley (2004) present an exception in the literature, since they do not make the a priori assumption that the wife is the secondary earner, but rather assume (ad hoc) that the spouse who is supposed to invest is the principal applicant for a visa to Australia.
} 
of consumption between the spouses. The more efficient investment due to marriage enables the achievement of a Pareto improvement.

Comparative statics analysis reveals that a proportional change in both spouses' imported human capital levels does not affect their optimal investments. However, the level invested by each spouse is non-increasing with the level of the imported human capital of the spouse with the comparative advantage in investment, whereas it is non-decreasing with the level of imported human capital of the other spouse. These results indicate that any empirical examination of the FIH should also control for the investigated spouse's imported human capital growth rate relative to that of his/her spouse and not only for their imported human capital levels (i.e., the wife and husband's years of schooling).

Finally, the model demonstrates that one cannot a priori expect that the investment of native couples with accessibility to a perfect capital market would be higher than the investment of credit-constrained immigrant couples (other things being equal). Liquidity constraints indeed act to reduce the immigrants’ investment in local skills, but the imported human capital growth effect acts in the opposite direction to augment their investment. It is therefore not surprising that researchers found that in some countries immigrant families invest more than their native counterparts, and vice versa in other countries. Specifically, the empirical support for the FIH reported in Baker and Benjamin (1997) for Canada and the opposite findings in Blau et al. (2003) for the U.S. can both emerge as special cases of our model.

\section{The Model}

In this section, a two-period model of the married immigrants' optimal investment in local human capital is developed. Following Eckstein and Weiss (2004), the human capital is partitioned into imported and locally acquired capital. Imported human capital is 
measured in terms of the productive capacity in the host country. The imported human capital grows with time in the host country, reflecting the process of the adaptation of the worker's imported skills to the local technology, whereas the quantities of locally acquired skills can vary due to investment in human capital on the job. Investment on the job requires loss of potential earnings during the first period, for future growth in the earning capacity. The two types of human capital (imported and locally acquired) are complements in their influence on the immigrant's earning capacity in the host country. Specifically, the earning capacities of an immigrant husband, $Y_{t h}$, an immigrant wife, $Y_{t w}$, and the couple, $Y_{t}$, at time $t, t=1,2$ are:

$$
Y_{t h}=R K_{0 h}^{t} K_{1 h}^{t}, \quad Y_{t w}=R K_{0 w}^{t} K_{1 w}^{t} \text { and } Y_{t}=Y_{t h}+Y_{t w},
$$

where $\mathrm{K}_{0 \mathrm{~h}}^{\mathrm{t}}$ and $\mathrm{K}_{0 \mathrm{w}}^{\mathrm{t}}$ are the husband and wife's imported human capital levels, respectively, $K_{1 h}^{t}$ and $K_{1 w}^{t}$ are the husband and wife's local human capital levels at time $t$, respectively, and $R$ is the human capital rental rate in the market. ${ }^{6}$

The local earnings of an immigrant couple at time $t, t=1,2$, are:

$$
y_{t}=y_{t h}+y_{t w}=Y_{t h}\left(1-x_{t h}\right)+Y_{t w}\left(1-x_{t w}\right)
$$

where $x_{t h}$ and $x_{t w}$ are the portions of earnings that are forgone as a result of the immigrant husband and his wife's investment on the job at time $t$, respectively. ${ }^{7}$

Each spouse's imported human capital grows with time in the host country at an exogenous rate $\beta_{\mathrm{j}}, j=w, h$, i.e., $\beta_{j}=\left(K_{0 j}^{2} / K_{0 j}^{1}\right)-1 .^{8}$ This growth rate reflects the adjustment process of the imported human capital with time spent in the new country. With

\footnotetext{
${ }^{6}$ In the following, the subscript $h$ refers to the husband and $w$ to the wife.

7 Bernhardt and Backus (1990) used a different approach to study the investment decisions of married couples. In their study, human capital is accumulated on the job and does not lead to a loss of earnings.

${ }^{8}$ For an immigrant who arrived with no imported human capital, $K_{0 j}^{1}$ is normalized to 1 and $\beta_{j}=0, \mathrm{j}=w, h$.
} 
no loss of generality, in the following analysis it is assumed that $\beta_{h}>\beta_{w}$. Following Blinder and Weiss (1976), the accumulation of local human capital is given by:

$$
K_{1 j}^{2}=K_{1 j}^{1}\left(1+g\left(x_{1 j}\right)-\delta\right) \quad j=w, h,
$$

where $K_{1 h}^{1}=K_{1 w}^{1}=1$ is a normalization, $\delta$ is the local human capital depreciation rate and $g\left(x_{t j}\right) \quad j=w, h$ is increasing and concave.

\section{A. The Family's Earnings Possibilities Frontier}

The family maximizes its inter-temporal utility. This requires an efficient production of the family's earnings regardless of the capital market structure. The family's Earnings Possibilities Frontier is derived by solving the following problem:

$$
\begin{aligned}
& \max _{x_{1 w}, x_{1 h}, x_{2 w}, x_{2 h}} y_{2} \\
& \text { s.t. } y_{1}=\text { constant, } \quad 0 \leq x_{t j} \leq 1, \quad t=1,2, \quad j=w, h .
\end{aligned}
$$

In the second period, which is the last work period, there is no incentive to invest on the job, i.e., $x_{2 w}=x_{2 h}=0$ and thus $y_{2}=Y_{2}$. Applying the Kuhn-Tucker Theorem for an interior solution to (4), the optimal first period investment policy is characterized by:

$$
\left(1+\beta_{w}\right) g_{x_{1 w}}^{\prime}=\left(1+\beta_{h}\right) g_{x_{1 h}}^{\prime},
$$

where $\quad g_{x_{1 j}}^{\prime}=\frac{\partial g}{\partial x_{1 j}}, \quad j=w, h$.

Equation (5) is equivalent to the following equation:

$$
-\frac{K_{0 h}^{1}}{K_{0 w}^{1}}=-\frac{K_{0 h}^{1}\left(1+\beta_{h}\right) g_{x_{1 h}}^{\prime}}{K_{0 w}^{1}\left(1+\beta_{w}\right) g_{x_{1 w}}^{\prime}} .
$$

The left-hand side of (6) is the slope of an iso $y_{1}$ in the $\left(1-x_{1 h}, 1-x_{1 w}\right)$ plane and the righthand side is the slope of an iso $y_{2}$. The tangency condition given by (6) is the necessary condition for maximization of $y_{2}$ for a given $y_{1}$, i.e., for an efficient investment by the 
family. Figure 1a presents the Contract Curve between the husband and his wife's investment in local skills. Interior solutions for the maximization problem in (5) are along $E_{1} E_{2}$ curve. $^{9}$

\section{Insert Figure 1 here}

Applying the Envelope Theorem for the case of an interior solution to (4), one gets the slope of the Earnings Possibilities Frontier when money can be transferred to the next period only via the channel of investment in local skills on the job:

$$
\frac{d y_{2}}{d y_{1}}=-\left(1+\beta_{w}\right) g_{x_{1 w}}^{\prime}=-\left(1+\beta_{h}\right) g_{x_{1 h}}^{\prime} \cdot 10
$$

In the cases of corner solutions, i.e., along the edge, the following inequality is satisfied:

$$
-\frac{K_{0 h}^{1}}{K_{0 w}^{1}}>-\frac{K_{0 h}^{1}\left(1+\beta_{h}\right) g_{x_{1 h}}^{\prime}}{K_{0 w}^{1}\left(1+\beta_{w}\right) g_{x_{1 w}}^{\prime}} .
$$

Given that $\beta_{h}>\beta_{w}$, corner solutions are part of the Earnings Possibilities Frontier under one of the following two conditions: $g^{\prime}(1) \neq 0$ or $g^{\prime}(0)<\infty$. The case where $g^{\prime}(1) \neq 0$ may lead to the allocation where the wife is the only spouse who works and the husband only invests (i.e., $\left.x_{1 h}=1,0<x_{1 w}<1\right)$. Likewise, if $g^{\prime}(0)<\infty$ it is also efficient that the husband is the only spouse who invests, if at all, and the wife only works (i.e., $0 \leq x_{1 h}<1, x_{1 w}=0$ ), see Figure $1 \mathrm{a} O_{1} E_{1}$ and $E_{2} O_{2}$, respectively. The case of full

${ }^{9}$ An iso- $y_{1}$ is linear, whereas the concavity of $g\left(x_{t j}\right)$ implies that an iso- $y_{2}$ is strictly convex. Thus, the tangency condition is also sufficient for maximization of $y_{2}$ for a given $y_{1}$.

${ }^{10}$ Given that $\beta_{h}>\beta_{w}$, it is assumed that $\frac{d y_{2}}{d y_{1}}=-\left(1+\beta_{w}\right) g^{\prime}(1)<-1$, i.e. the family would always prefer to transfer money to the next period via investment on the job rather than store the cash. However, in the next section we show that the above assumption does not affect the solution under binding liquidity constraints. 
specialization, where the husband only invests and the wife only works, may occur only if both conditions, $g^{\prime}(1) \neq 0$ and $g^{\prime}(0)<\infty$, are met.

The slopes of the Earnings Possibilities Frontier for the above-mentioned cases of corner solutions to (4), i.e., $x_{1 h}=1$ or $x_{1 w}=0$, are, respectively:

$$
\frac{d y_{2}}{d y_{1}}=-\left(1+\beta_{w}\right) g_{x_{1 w}}^{\prime}>-\left(1+\beta_{h}\right) g_{x_{1 h}}^{\prime}
$$

and

$$
\frac{d y_{2}}{d y_{1}}=-\left(1+\beta_{h}\right) g_{x_{1 h}}^{\prime}<-\left(1+\beta_{w}\right) g_{x_{1 w}}^{\prime} \text {. }
$$

From the concavity of $g\left(x_{t j}\right)$ and from (6'), (7') and (7'’) it follows that the Earnings Possibilities Frontier, $y_{2}=f\left(y_{1}\right)$, (see Figure 1b) is concave and its slope depends either on $x_{1 h}$ (which is a non-decreasing function of $x_{1 w}$ ) in the range $E_{1} O_{2}$ or on $X_{1 w}$ in the range $O_{1} E_{1}$ (see Figure 1a).

\section{B. The Effect of the Capital Market Structure on Investment}

First consider a perfect capital market in which every family can borrow and lend freely at a fixed interest rate, $r$, as a benchmark. Under a perfect capital market, investment and consumption decisions can be separated. The family maximizes the present value of its lifetime earnings:

$$
\max _{y_{1}} y_{1}+\frac{f\left(y_{1}\right)}{1+r} .
$$

The optimal first period investment policy for an interior solution is characterized by:

$$
-\frac{d y_{2}}{d y_{1}}=\left(1+\beta_{w}\right) g_{x_{1 w}}^{\prime}=\left(1+\beta_{h}\right) g_{x_{1 h}}^{\prime}=1+r
$$


and the optimal consumption is characterized by:

$$
\frac{V_{y_{1}}}{V_{y_{2}}}=1+r \text {, where } V_{y_{t}}=\frac{\partial V\left(y_{1}, y_{2}\right)}{\partial y_{t}} \quad t=1,2,
$$

where the indirect utility function $V\left(y_{1}, y_{2}\right)$ is increasing and concave. The optimal investment policy given by (9) is independent of the imported human capital levels of both spouses and of his/her spouse's human capital growth. Therefore, the optimal investment of each partner is not influenced by the marital status. However, the person with the lower imported human capital growth rate will work relatively more.

The possibility to lend or borrow at a fixed interest rate, $r$, may lead the family to consume at a different point than its production (earnings) point. To illustrate this case, consider point $B_{2}$ in Figure $1 \mathrm{~b}$ that satisfies (9) and represents the family's production. Utility maximization, however, would lead the family to consume at point $\mathrm{C}$, which means that the family borrows during the first period (in order to finance the investment, at least partially).

Let $r^{*}$ be the interest rate such that under a perfect capital market the family will not borrow and will not lend, but will transfer money to the next period through investment on the job, if at all. In fact, $-\left(1+r^{*}\right)$ is the slope of the family's (indirect) indifferent curve at the point of tangency to the Earnings Possibilities Frontier (see point $B_{1}$ in Figure 1b). By definition, liquidity constraints are binding if the family would like to borrow in the market interest rate, $r$, but in practice it cannot do so. That is, the competitive interest rate $r$ is lower than $r^{*}$.

Given that the family faces binding liquidity constraints, it must decide on $a$ ) the level of each spouse's investment on the job and, $b$ ) the partition of consumption (earnings) between the spouses. For an efficient allocation of consumption between the spouses, the utility of one spouse is necessarily maximized for any given utility level of the other 
spouse. In order to concentrate on the influence of marriage on the investment decisions, it is assumed that each spouse's utility is a function of his/her own consumption only. In addition, we also assume a separable inter-temporal utility. The objective of the family is then:

$$
\begin{aligned}
& \max _{\substack{x_{1 w}, x_{1 h}, x_{2 w}, x_{2 h} \\
c_{1 w}, c_{1 h}, c_{2 w}, c_{2 h}}} U^{h}\left(c_{1 h}\right)+\frac{U^{h}\left(c_{2 h}\right)}{1+\rho} \\
& \text { s.t.: (i) } U^{w}\left(c_{1 w}\right)+\frac{U^{w}\left(c_{2 w}\right)}{1+\rho}=\text { constant, } \\
& \text { (ii) } y_{t}=c_{t h}+c_{t w} \quad t=1,2,
\end{aligned}
$$

where $U^{j}$ and $c_{t j} \quad j=w, h \quad t=1,2$, are each spouses' utility function and consumption, respectively, and $\rho \geq 0$ is the time preference rate. Again, there is no incentive to invest on the job during the second period, which is the last work period, i.e., $x_{2 w}=x_{2 h}=0$ and thus $y_{2}=Y_{2}$.

The first order conditions for an interior solution to (10) are:

$$
\left(1+\beta_{w}\right) g_{x_{1 w}}^{\prime}=\left(1+\beta_{h}\right) g_{x_{1 h}}^{\prime}=\frac{U_{c_{1}}^{h}(1+\rho)}{U_{c_{2}}^{h}}=\frac{U_{c_{1}}^{w}(1+\rho)}{U_{c_{2}}^{w}} .
$$

The right-hand side of (11) is a necessary condition for any efficient allocation of intertemporal consumption (herewith - efficient allocation condition). However, without additional assumptions the two decisions (a) and (b) above should be solved simultaneously, i.e., each spouse's optimal investment level may depend on the partition of consumption between the spouses.

Lemma 1: If both spouses have identical preferences presented by a homothetic utility function, $U$, all the partitions of consumption (earnings) between them that satisfy 
the efficient allocation condition correspond to the same outcome on the Earnings Possibilities Frontier. ${ }^{11}$

Proof: Assuming identical homothetic preferences, without loss of generality, (11) can be written as:

$$
\left(1+\beta_{w}\right) g_{x_{1 w}}^{\prime}=\left(1+\beta_{h}\right) g_{x_{1 h}}^{\prime}=\frac{c_{2 h}(1+\rho)}{c_{1 h}}=\frac{\left(y_{2}-c_{2 h}\right)(1+\rho)}{y_{1}-c_{1 h}},
$$

or alternately,

$$
\left(1+\beta_{w}\right) g_{x_{1 w}}^{\prime}=\left(1+\beta_{h}\right) g_{x_{1 h}}^{\prime}=\frac{c_{2 h}(1+\rho)}{c_{1 h}}=\frac{y_{2}(1+\rho)}{y_{1}}
$$

Since the left-hand side of (12') is a decreasing function of $x_{1 w}$ and $x_{1 h}$, whereas the righthand side is an increasing function of $x_{1 w}$ and $x_{1 h}$, there is a unique solution to (12') regardless of the allocation of consumption between the spouses.

Under binding liquidity constraints one obtains:

$$
\left(1+\beta_{w}\right) g_{x_{1 w}}^{\prime}=\left(1+\beta_{h}\right) g_{x_{1 h}}^{\prime}=\frac{y_{2}(1+\rho)}{y_{1}}=1+r^{*}>1+r
$$

Thus, due to binding liquidity constraints in the case of an interior solution, both spouses will work more (invest less). However, in the case of a corner solution, if the tangency points $\left(B_{1}\right.$ and $B_{2}$ ) are to the left of $E_{1}$ only the wife will work more, whereas if the tangency points are to the right of $E_{2}$ only the husband will work more. That is, under binding liquidity constraints, the family consumes and produces at point $B_{1}$ (where the family's indifferent curve is tangent to the Earnings Possibilities Frontier) instead of producing at point $B_{2}$ (which is located to the left of $B_{1}$ ) and consuming at point $C$, by using the capital market to finance the earning gap (see Figure 1b).

11 Browning and Chiappori (1998) show that when deriving the household demand, identical preferences allow for using the conventional "unitary" model i.e., the family is maximizing the utility of one of the spouses under the household budget constraint. 
According to (9), under a perfect capital market, each spouse's imported human capital level will not affect the family members' investment decision. However, in the following section it is shown that under binding liquidity constraints the investment decision of each family member is affected by his/her own and his/her spouse's imported human capital level.

Lemma 2: $x_{1 w}\left(K_{0 w}, K_{0 h}\right)$ and $x_{1 h}\left(K_{0 w}, K_{0 h}\right)$ are homogeneous functions of degree 0 in $K_{0 w}$ and $K_{0 h}$.

Proof: Multiplying $K_{0 w}$ and $K_{0 h}$ by a scalar $\lambda>0$ is equivalent to changing the scale of both axes in Figure 1b accordingly, where the graph of the Earnings Possibilities Frontier will not move. Thus, both spouses’ optimal investment in the local human capital $x_{1 w}\left(K_{0 w}, K_{0 h}\right)$ and $x_{1 h}\left(K_{0 w}, K_{0 h}\right)$ will not change either.

Lemma 3: In the case of interior solutions, if $\beta_{w}<\beta_{h}$ then

$$
\frac{\partial x_{1 h}}{\partial K_{0 h}^{1}}<0, \frac{\partial x_{1 w}}{\partial K_{0 w}^{1}}>0, \frac{\partial x_{1 h}}{\partial K_{0 w}^{1}}>0 \text { and } \frac{\partial x_{1 w}}{\partial K_{0 h}^{1}}<0
$$

See proof in Appendix A.

Given that each spouse has a different $\beta$, it follows from Lemma 3 that the effect of an increase in the imported human capital level on the human capital investment is asymmetric. Specifically, an increase in the level of imported skills of the spouse with the higher imported human capital growth rate leads to a decrease in the investment of the two spouses, while the same increase experienced by his/her spouse increases both spouses' investment.

\section{Investment of Single Versus Married Immigrants}

In the following section, we compare the investment in local human capital of singles and married immigrants. The optimal investment policy under a perfect capital 
market (given by (9)) holds regardless of whether a marriage takes place. However, under binding liquidity constraints it is influenced by the marital status. In the following Lemma, it is shown that a single man who marries would increase his investment in local skills, whereas a single woman who marries would decrease her investment in local skills (recall that $\beta_{h}>\beta_{w}$ ). These changes allow for an increase in the utility of one spouse without decreasing the utility of the other, compared to their utility as single persons. Marriage can thus lead to a Pareto improvement.

Lemma 4: Let $x_{1 w}^{s}, x_{1 h}^{s}, x_{1 w}^{m}, x_{1 h}^{m}$ be the optimal investment during period 1 of a single woman and man, and a married wife and husband, respectively. Assuming that the spouses have identical preferences presented by a homothetic utility function, then $x_{1 w}^{s}=x_{1 h}^{s}=x^{*}, \quad x_{1 w}^{s}>x_{1 w}^{m}$ and $x_{1 h}^{s}<x_{1 h}^{m}$.

Proof: Under the assumptions of Lemma 1 (i.e., identical and homothetic preferences of the spouses), without loss of generality, the slopes of each individual's indifferent curve and of the family's corresponding indifferent curve are equal to $\frac{U_{y_{1}}(1+\rho)}{U_{y_{2}}}=\frac{y_{2}}{y_{1}}(1+\rho)$. Thus, the first order conditions for the maximization of each single immigrant’s utility are:

$$
\frac{y_{2 j}}{y_{1 j}}(1+\rho)=\frac{K_{0 j}^{1}\left(1+\beta_{j}\right)\left(1+g\left(x_{1 j}^{s}\right)-\delta\right)(1+\rho)}{K_{0 j}^{1}\left(1-x_{1 j}^{s}\right)}=\left(1+\beta_{j}\right) g_{x_{1 j}^{s}}^{\prime} \quad j=w, h,
$$

or, alternatively:

$$
\frac{\left(1+g\left(x_{1 j}^{s}\right)-\delta\right)(1+\rho)}{\left(1-x_{1 j}^{s}\right)}=g_{x_{1 j}^{s}}^{\prime} \quad j=w, h
$$

Therefore, each single immigrant makes the same investment independently of his/her imported human capital level and its growth rate, i.e.,:

$$
x_{1 w}^{s}=x_{1 h}^{s}=x * .
$$


Thus, condition (5) for efficient investment after marriage, which implies that $x_{1 h}^{m}>x_{1 w}^{m}$, is violated pre-marriage. In order to characterize each spouse's optimal investment relative to his/her investment as a single person, it is first assumed that both spouses have the same imported human capital level. The first order conditions for maximization of the family's utility will then be:

$$
B\left(x_{1 w}^{m}, x_{1 h}^{m}\right)=\frac{\sum_{i=w, h}\left(1+\beta_{i}\right)\left(1+g\left(x_{1 i}^{m}\right)-\delta\right)(1+\rho)}{\left(1-x_{1 h}^{m}\right)+\left(1-x_{1 w}^{m}\right)}=\left(1+\beta_{j}\right) g_{x_{1 j}^{m}}^{\prime} \quad j=w, h .
$$

Since $x_{1 w}^{m}<x_{1 h}^{m}$ it follows from (16) that:

$$
\frac{\left(1+\beta_{h}\right)\left(1+g\left(x_{1 h}^{m}\right)-\delta\right)(1+\rho)}{\left(1-x_{1 h}^{m}\right)}>B=\left(1+\beta_{h}\right) g_{x_{1 h}^{m}}^{\prime}
$$

and

$$
\frac{\left(1+\beta_{w}\right)\left(1+g\left(x_{1 w}^{m}\right)-\delta\right)(1+\rho)}{\left(1-x_{1 w}^{m}\right)}<B=\left(1+\beta_{w}\right) g_{x_{1 w}^{m}}^{\prime}
$$

The left-hand sides of (17) and (18) are increasing functions of $x_{1 j} j=w, h$, whereas the right-hand sides decrease with $x_{1 j} j=w, h$. Therefore, from (14'), (16) ,(17) and (18) it follows that:

$$
x_{1 w}^{s}>x_{1 w}^{m} \text { and } x_{1 h}^{s}<x_{1 h}^{m} \text {. }
$$

That is, if both spouses have the same imported human capital level, $K_{0 w}^{1}=K_{0 h}^{1}$, marriage changes the optimal investment such that the spouse with the higher imported human capital growth rate (the husband in our model) invests more and his partner (the wife) invests less. These results are more general and also hold if the spouses have different imported human capital levels. To prove the general case, let us begin with $K_{0 w}^{1}=K_{0 h}^{1}$. According to Lemma 3, an increase in $K_{0 w}^{1}$ results in an increase in both $x_{1 h}^{m}$ and $x_{1 w}^{m}$. The inequality in (19) for the husband is therefore strengthened even more, whereas the inequality for the wife is weakened (recall that a single immigrant's investment 
is independent of her/his imported human capital level). However, the wife's inequality cannot be reversed, since her investment after marriage will never reach $x *$. To see this recall that if it reaches $x^{*}$ then $x_{1 w}^{m}=x^{*}<x_{1 h}^{m}$ satisfies the first order condition of a married woman, $B\left(x^{*}, x_{1 h}^{m}\right)=\left(1+\beta_{w}\right) g_{x^{*}}^{\prime}$ (equation (16)) and the first order condition of a single woman, $\left(1+\beta_{w}\right) g_{x^{*}}^{\prime}=\frac{\left(1+\beta_{w}\right)\left(1+g\left(x^{*}\right)-\delta\right)(1+\rho)}{\left(1-\chi^{*}\right)}$ (equation (14')). However, $\frac{\left(1+\beta_{w}\right)\left(1+g\left(x^{*}\right)-\delta\right)(1+\rho)}{\left(1-x^{*}\right)}<B\left(x^{*}, x^{*}\right)<B\left(x^{*}, x_{1 h}^{m}\right)$ such that the contradiction, $\left(1+\beta_{w}\right) g_{x^{*}}^{\prime}<\left(1+\beta_{w}\right) g_{x^{*}}^{\prime}$ is obtained. In the same manner, it can be seen from Lemma 3 that an increase in $K_{0 h}^{1}$ results in a decrease in both $x_{1 h}^{m}$ and $x_{1 w}^{m}$. The wife's inequality in (19) is thus even strengthened, whereas the husband's inequality is weakened, although it will never again reach $x *$. The husband's investment therefore cannot be reversed.

\section{Investment of Immigrant Families Compared to Native Families}

Our framework contains two elements that distinguish immigrants from natives. The first is that natives face a perfect capital market, whereas immigrants may face binding liquidity constraints upon arrival in the new country. The second element is that natives acquire only local human capital, and therefore cannot benefit from the exogenous growth rate of imported human capital.

Due to these differences, the optimal first period investment policy of native couples is characterized by (instead of by (13) for immigrants):

$$
g_{x_{1 w}}^{\prime}=g_{x_{1 h}}^{\prime}=1+r
$$

From (13) and (20) it appears that it is impossible to predict a priori whether immigrants will invest more or less in local skills than their native counterparts. The 
immigrant spouse for whom $\frac{1+r^{*}}{1+\beta_{j}} \geq 1+r, \quad j=w, h$ will invest no more (will work no less) than his/her native counterpart and vice versa for the spouse with $\frac{1+r^{*}}{1+\beta_{j}} \leq 1+r, \quad j=w, h$

These results are compatible with the empirical findings of Baker and Benjamin (1997) that immigrant women's labor-market participation upon arrival in Canada is higher than that of native women, and also with the opposite results obtained by Blau et al. (2003) for the U.S. Both findings may emerge as special cases of our model, depending on the value of the parameters.

\section{Concluding Remarks}

The present paper provides a two-period theoretical framework for exploring the predictions of the Family Investment Hypothesis. The optimal level of investment in local skills of an immigrant family that acts under binding liquidity constraints is characterized compared to the optimal investment of a single immigrant and native families that face a perfect capital market.

The findings indicate that each family member's optimal investment level in local skills depends on both spouses' imported human capital growth rate and not solely on their imported human capital level. The imported human capital growth rate is a special feature of the immigrants' adjustment process to the new-country economy. To date, the empirical literature on family investment assumed that the investment in local skills depends, among other things, on the absolute number of years of schooling, i.e., on the imported human capital level. However, it is not clear whether the investment in local skills of two immigrants with the same years of schooling, for example a physician and a physicist, should be identical (other things being equal). Immigrants with an identical imported 
human capital level may face different imported human capital growth rates, depending on the difference in the technologies between their home country and the destination country. In the above example, it can be argued that the adjustment process of the physician's imported skills is more difficult than the physicist's. The absorption of these two immigrants can therefore be different despite their identical imported human capital level. Imported human capital growth may depend on the imported occupation, the country of origin, the age at arrival, etc. 


\section{References}

Baker, Michael and Dwayne Benjamin. 1997. "The Role of the Family in Immigrants' Labour Market Activity: An Evaluation of Alternative Explanations.” American Economic Review, 87(4): 5-27.

Beach, Charles M. and Christopher Worswick. 1993. "Is There a Double-Negative Effect on the Earnings of Immigrant Women?” Canadian Public Policy, 19(1): 36-53.

Bernhardt, Dan and David Backus. 1990. "Borrowing Constraints, Occupational Choice, and Labor Supply.” Journal of Labor Economics, 8(1): 145-173.

Blau, Francine D., Lawrence M. Kahn, Joan Y. Moriarty and Andre Portela Souza. 2003. "The Role of the Family in Immigrants' Labor Market Activity: An Evaluation of Alternative Explanations- Comment.” American Economic Review, 93(1): 429-447.

Blinder, Alan S. and Yoram Weiss. 1976. "Human Capital and Labor Supply: a Synthesis.” Journal of Political Economy, 75(4): 352-65.

Browning, Martin and Pierre A. Chiappori. 1998. "Efficient Intra-Household Allocations: A General Characterization and Empirical Tests." Econometrica, 66(6):1241-1278.

Cobb-Clark, Deborah and Thomas F. Crossley. 2004. "Revisiting the Family Investment Hypothesis.” Labour Economics, 11(3): 373-393.

Duleep, Harriet Orcutt and Daniel J. Dowhan. 2002. "Revisiting the Family Investment Model with Longitudinal Data: The Earnings Growth of Immigrant and U.S.-Born Women.” Forschunsinstitut zur Zukunft der Arbeit (IZA) Discussion Paper 568.

Duleep, Harriet Orcutt and Mark C. Regets. 1999. "Immigrants and Human-Capital Investment.” American Economic Review, 89(2): 186-191.

Duleep, Harriet Orcutt and Seth Sanders. 1993. "The Decision to Work by Married Immigrant Women.” Industrial and Labor Relations Review, 46(4): 67-80.

Eckstein, Zvi and Yoram Weiss. 2004. "On the Wage Growth of Immigrants: Israel 19902000.” Journal of the European Economic Association, 2(4): 665-695.

Long, James, E. 1980. "The Effect of Americanization on Earnings: Some Evidence for Women.” Journal of Political Economy, 88(3): 620-29.

Weiss, Yoram. 1997. "The Formation and Dissolution of Families: Why Marry, Who Marries Whom, and What Happens Upon Marriage and Divorce?” in Rosenzweig, M. and O. Stark (eds.), Handbook of Population Economics, Elsevier.

Worswick, Christopher. 1996. "Immigrant Families in the Canadian Labour Market." Canadian Public Policy, 22(4): 378-396.

Worswick, Christopher. 1999. "Credit Constraints and the Labor Supply of Immigrant Families in Canada.” Canadian Journal of Economics, 32(1): 152-170. 
Figure 1:The Optimal Investment of Immigrant Couples
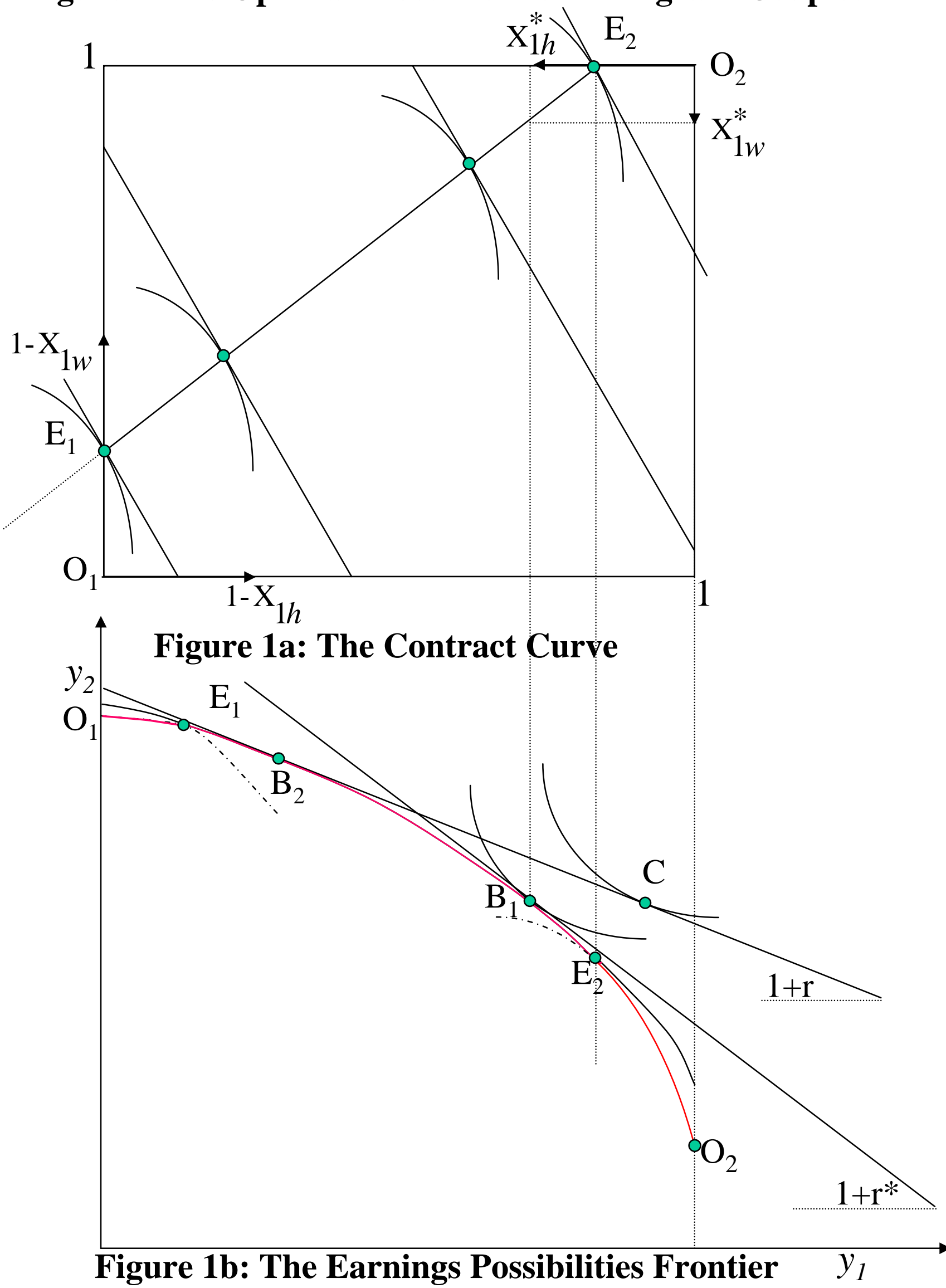


\section{Appendix $A$}

Proof of Lemma 3: Under the assumptions of Lemma 1 (i.e., identical and homothetic preferences of the spouses), without loss of generality, the slopes of each partner's indifferent curve and of the corresponding family's indifferent curve is equal to $\frac{U_{y_{1}}(1+\rho)}{U_{y_{2}}}=\frac{y_{2}}{y_{1}}(1+\rho) .{ }^{1}$ Totally differentiating the first order conditions for maximization

(13) results in:

(A1)

$$
a_{11} d x_{1 w}+a_{12} d x_{1 h}=E_{w} d K_{0 w}^{1}+E_{h} d K_{0 h}^{1}
$$$$
a_{21} d x_{1 w}+a_{22} d x_{1 h}=E_{w} d K_{0 w}^{1}+E_{h} d K_{0 h}^{1},
$$

$$
\begin{aligned}
& \text { where } a_{11}=\frac{\left(1+\beta_{w}\right) y_{1}^{2} g_{x_{1 w}}^{\prime \prime}-K_{0 w}^{2} g_{x_{1 w}}^{\prime} y_{1}(1+\rho)-K_{0 w}^{1} y_{2}(1+\rho)}{y_{1}^{2}(1+\rho)}, \\
& a_{12}=\frac{-K_{0 h}^{2} g_{x_{1 h}}^{\prime} y_{1}-K_{0 h}^{1} y_{2}}{y_{1}^{2}}, a_{21}=\frac{-K_{0 w}^{2} g_{x_{1 w}}^{\prime} y_{1}-K_{0 w}^{1} y_{2}}{y_{1}^{2}}, \\
& a_{22}=\frac{\left(1+\beta_{h}\right) y_{1}^{2} g_{x_{1 h}}^{\prime \prime}-K_{0 h}^{2} g_{x_{1 h}}^{\prime} y_{1}(1+\rho)-K_{0 h}^{1} y_{2}(1+\rho)}{y_{1}^{2}(1+\rho)}, \\
& E_{w}=\frac{\partial \frac{y_{2}}{y_{1}}}{\partial K_{0 w}^{1}}=\frac{\left(1+\beta_{w}\right)\left(1+g\left(x_{1 w}\right)-\delta\right) y_{1}-\left(1-x_{1 w}\right) y_{2}}{y_{1}^{2}},
\end{aligned}
$$

and

$$
E_{h}=\frac{\partial \frac{y_{2}}{y_{1}}}{\partial K_{0 h}^{1}}=\frac{\left(1+\beta_{h}\right)\left(1+g\left(x_{1 h}\right)-\delta\right) y_{1}-\left(1-x_{1 h}\right) y_{2}}{y_{1}^{2}}
$$

Substituting $y_{1}$ and $y_{2}$ into $E_{w}$ and $E_{h}$ result in:

$$
E_{w}=\frac{K_{0 h}^{1}\left(\left(1+\beta_{w}\right)\left(1+g\left(x_{1 w}\right)-\delta\right)\left(1-x_{1 h}\right)-\left(1+\beta_{h}\right)\left(1+g\left(x_{1 h}\right)-\delta\right)\left(1-x_{1 w}\right)\right)}{y_{1}^{2}},
$$

and

${ }^{1}$ In principle, the same proof holds for each $M R S$ which is a positive monotonic transformation of the above MRS. 
(A3) $E_{h}=\frac{K_{0 w}^{1}\left(\left(1+\beta_{h}\right)\left(1+g\left(x_{1 h}\right)-\delta\right)\left(1-x_{1 w}\right)-\left(1+\beta_{w}\right)\left(1+g\left(x_{1 w}\right)-\delta\right)\left(1-x_{1 h}\right)\right)}{y_{1}^{2}}$.

Assuming that $\beta_{w}<\beta_{h}$ one obtains $x_{1 w}<x_{1 h}$ and thus: $\frac{\partial \frac{y_{2}}{y_{1}}}{\partial K_{0 w}^{1}}=E_{w}<0$, and $\partial \frac{y_{2}}{y_{1}}$ $\frac{y_{1}}{\partial K_{0 h}^{1}}=E_{h}>0$.

Solving for $\frac{\partial x_{1 h}}{\partial K_{0 h}^{1}}, \frac{\partial x_{1 h}}{\partial K_{0 w}^{1}}, \frac{\partial x_{1 w}}{\partial K_{0 h}^{1}}$, and $\frac{\partial x_{1 w}}{\partial K_{0 w}^{1}}$ one obtains:

(A4) $\frac{\partial x_{1 h}}{\partial K_{0 h}^{1}}=\frac{E_{h}\left(1+\beta_{w}\right) g_{x_{1 w}}^{\prime \prime}}{|A|(1+\rho)}<0, \frac{\partial x_{1 h}}{\partial K_{0 w}^{1}}=\frac{E_{w}\left(1+\beta_{w}\right) g_{x_{1 w}}^{\prime \prime}}{|A|(1+\rho)}>0$,

$$
\frac{\partial x_{1 w}}{\partial K_{0 h}^{1}}=\frac{E_{h}\left(1+\beta_{h}\right) g_{x_{1 h}}^{\prime \prime}}{|A|(1+\rho)}<0 \text {, and } \frac{\partial x_{1 w}}{\partial K_{0 w}^{1}}=\frac{E_{w}\left(1+\beta_{h}\right) g_{x_{1 h}}^{\prime \prime}}{|A|(1+\rho)}>0 \text {, }
$$

where $|A|=a_{11} a_{22}-a_{12} a_{21}>0$. 